\title{
Aromatase Cytochrome P450 and Extragonadal Estrogen Play a Role in Ischemic Neuroprotection
}

\author{
Louise D. McCullough, ${ }^{1,2}$ Kathleen Blizzard, ${ }^{2}$ Evan R. Simpson, ${ }^{3}$ Orhan K. Öz, ${ }^{4}$ and Patricia D. Hurn ${ }^{5}$ \\ ${ }^{1}$ Department of Neurology and Anesthesiology and ${ }^{2}$ Critical Care Medicine, Johns Hopkins School of Medicine, Baltimore, Maryland 21287, ${ }^{3}$ Victorian Breast \\ Cancer Consortium, Prince Henry's Institute of Medical Research, Victoria 3168, Australia, ${ }^{4}$ University of Texas Southwestern Medical Center at Dallas, Dallas, \\ Texas 75390, and ${ }^{5}$ Department of Anesthesiology and Perioperative Medicine, Oregon Health Sciences University, Portland, Oregon 97239-3098
}

Female animals are protected from many forms of neurological injury and degeneration relative to their male counterparts, in part attributable to their native estrogens. We hypothesized that estradiol aromatized from precursor androgens via the cytochrome P450 aromatase contributes to ischemic neuroprotection in the female. Female homozygous aromatase knock-out (ArKO) mice and randomly cycling, wild-type (WT) female littermates were treated with reversible middle cerebral artery occlusion ( $90 \mathrm{~min} ; 22 \mathrm{hr}$ reperfusion). Total and regional ischemic damage was greater in female ArKOs (total, $33.5 \pm 4.8 \%$; cortical, $47.4 \pm 5.7 \%$; striatal, 44.8 $\pm 7.8 \%$ ) compared with WT (total, $14.2 \pm 5 \%$; cortical, $14.2 \pm 4.5 \%$; striatal, $17.5 \pm 8 \%$ ). Baseline blood pressure and intra-ischemic cortical perfusion were comparable in knock-outs and WT, suggesting that vascular factors do not explain ArKO ischemic sensitivity. Injury was smaller in ovariectomized WT than in ArKO, emphasizing that extragonadal local estradiol plays a critical role in females. Similar increases in cortical and striatal damage were observed in female WT mice chronically treated with the aromatase inhibitor fadrozole compared with vehicle-treated control mice. Restoration of plasma $17 \beta$-estradiol to physiological levels completely reversed the ArK0 female's susceptibility to injury. These findings indicate that the biosynthetic enzyme P450 aromatase is key to endogenous neuroprotection in females and suggest that enhancing local, nongonadal estrogen formation could have therapeutic implications is ischemic neuropathology.

Key words: aromatase; ischemia; neuroprotection; estrogen; gender; stroke

\section{Introduction}

Outcome from experimental stroke and cerebral ischemia is strongly dependent on sex and hormone status. As in women, female animals are protected from ischemic neuronal damage relative to their age-matched male counterparts when confronted with an ischemic stress (Alkayed et al., 1998). Ischemic injury volume has been correlated with the amount of circulating native estrogens, with the smallest strokes occurring in proestrus when estrogen (E2) levels are highest (Carswell et al., 2000). Loss of endogenous estrogen, through pharmacological inhibition, surgical ovariectomy, or reproductive senescence, eliminates this benefit (Alkayed et al., 1998, 2000; Rusa et al., 1999; Sawada et al., 2000). The final step in physiological synthesis of $17 \beta$-estradiol is aromatization of precursor testosterone by a CYP 19 gene product, cytochrome $\mathrm{P} 450$ estrogen aromatase, in the $\mathrm{C}_{19}$ steroid metabolic pathway. The role of this biosynthetic enzyme in ischemic injury in the female is not known.

The abundance and activity of the aromatase in rodents and humans have been well characterized in the CNS (for review, see

Received June 2, 2003; revised July 20, 2003; accepted Aug. 4, 2003.

This work was supported by the American Heart Association (L.D.M.), the Hazel K. Goddess Fund for Stroke Research in Women (L.D.M.), and the National Institutes of Health (P.D.H., O.K.O., E.R.S.).

Correspondence should be addressed to Dr. Louise McCullough, Department of Neurology, 600 North Wolfe Street, Pathology 509, Johns Hopkins University School of Medicine, Baltimore, MD 21287-4961. E-mail: louisemc@jhmi.edu.

Copyright $\odot 2003$ Society for Neuroscience $\quad$ 0270-6474/03/238701-05\$15.00/0
Lephart, 1996; Stoffel-Wagner et al., 1999; Lephart et al., 2001). Rodent brain aromatase activity is present in neocortex and archicortex, regionally heterogenous, and likely under developmental regulation (MacLusky et al., 1994). However, aromatase expression increases in male brain after domoic acid injection, suggesting that injury as well as development stage influence enzyme activity, increasing local tissue estrogen synthesis (Azcoitia et al., 2001). We and others have speculated that an important endogenous mechanism of ischemic neuroprotection in the female is intricately involved with recapitulation of developmental patterns of estradiol production and signaling. If so, then loss of P450 aromatase function would play a pivotal role in cell death after cerebral ischemia.

Recently, mice with targeted disruption of exon 9 of the CYP 19 gene [aromatase knock-out (ArKO)] have been developed (Fisher et al., 1998). Unlike other models of estradiol insufficiency [e.g., estrogen receptor (ER) knock-out mice], ArKOs cannot synthesize estrogen but retain some ability to respond to exogenous estrogen. The ArKO phenotype is characterized as one of low plasma estradiol, elevated testosterone, small atrophic uteri, decreased fertility, increased adiposity, decreased bone mass, and abnormal sexual behavior (Fisher et al., 1998; Robertson et al., 1999; Jones et al., 2000; Oz et al., 2000; Bakker et al., 2002). Here we test the hypothesis that loss of gonadal and nongonadal estrogen production via the P450 aromatase averts endogenous ischemic neuroprotection in the female brain and increases cell death. 
Table 1. Physiological parameters during MCAO were equivalent in all four groups of female mice in experiment 1

\begin{tabular}{|c|c|c|c|c|c|c|}
\hline Group & $\mathrm{pH}$ & $\mathrm{PaCO}_{2}$ & $\mathrm{PaO}_{2}$ & $\mathrm{Hg}$ & Glucose & MAP \\
\hline $\mathrm{WT}(n=11)$ & $7.38 \pm 0.01$ & $40 \pm 2$ & $151 \pm 8$ & $13.1 \pm 1.2$ & $155 \pm 8$ & $78 \pm 4$ \\
\hline $\operatorname{ArKO}(n=9)$ & $7.39 \pm 0.01$ & $39 \pm 2$ & $161 \pm 5$ & $12.6 \pm 1.1$ & $163 \pm 12$ & $76 \pm 3$ \\
\hline WT OVX $(n=11)$ & $7.41 \pm 0.01$ & $40 \pm 2$ & $160 \pm 10$ & $12.5 \pm 2.3$ & $164 \pm 13$ & $80 \pm 6$ \\
\hline $\operatorname{ArKO}+\mathrm{E} 2(n=9)$ & $7.41 \pm 0.03$ & $41 \pm 2$ & $159 \pm 6$ & $13.1 \pm 2.1$ & $164 \pm 4$ & $79 \pm 5$ \\
\hline
\end{tabular}

$\mathrm{Hg}$, Hemoglobin; MAP, mean arterial pressure.

\section{Materials and Methods}

Experimental animals. The present study was conducted in accordance with National Institutes of Health guidelines for the care and use of animals in research and under protocols approved by the Animal Care and Use Committee of the Johns Hopkins University. Female age- and weight-matched ArKOs were compared in all protocols with their wildtype (WT) littermates. ArKO mice were generated by targeted disruption of exon 9 of the CYP 19 gene [hybrid 129S6/SvEv (Taconic, Germantown, NY) C57BL/ 6 background], leading to nondetectable estrogen levels and high levels of gonadotrophins. ArKO females have higher testosterone levels compared with female littermates (testosterone in ArKO, $2350 \pm 432 \mathrm{pg} / \mathrm{ml}$; female WT, $260.2 \pm 38 \mathrm{pg} / \mathrm{ml}$ ) but lower levels than those seen in intact males (male WT, $2850 \pm 303 \mathrm{pg} / \mathrm{ml}$ ) (Fisher et al., 1998). Mice were genotyped by PCR using tail DNA as described previously (Robertson et al., 1999).

In additional protocols, gonadally intact and ovariectomized (OVX) adult female C57BL/6 mice (The Jackson Laboratory, Bar Harbor, ME) were treated with saline vehicle or the selective aromatase inhibitor fadrozole (CGS 16949A; 4-(5,6,7,8-tetraydroimidazol [1,5]-pyridin-5yl) benzonitrile monohydrochloride; generous gift from Novartis, Summit, NJ) via a subscapular osmotic minipump (flow rate of $0.5 \mu \mathrm{l} / \mathrm{hr} ; 0.50$ $\mathrm{mg} \cdot \mathrm{kg}^{-1} \cdot \mathrm{d}^{-1}$ for $7 \mathrm{~d}$; Alzet 2002; Alza, Palo Alto, CA) as described previously (Azcoitia et al., 2001). The rationale for fadrozole dosage and duration of administration was based on its near complete inhibition of enzyme activity in brain (Steele et al., 1987; Bonsall et al., 1992; Wade et al., 1994; Azcoitia et al., 2001).

Ischemic model. Cerebral ischemia was induced by $90 \mathrm{~min}$ of reversible middle cerebral artery occlusion (MCAO) under halothane anesthesia, as described previously (Sampei et al., 2000; Sawada et al., 2000). Rectal muscle temperatures were monitored with a MONO-THERM system (Mallinckrod Medical, St. Louis, MO) and maintained at $\sim 37^{\circ} \mathrm{C}$ during surgery and ischemia. A midline ventral neck incision was made, and unilateral MCAO was performed by inserting a 6.0 nylon monofilament into the internal carotid artery $6 \mathrm{~mm}$ from the internal carotid-pterygopalatine artery bifurcation via an external carotid artery stump. Intraischemic neurological deficit was confirmed and scored as follows: 0 , no deficit; 1 , forelimb weakness and torso turning to the ipsilateral side when held by tail; 2 , circling to affected side; 3 , unable to bear weight on affected side; and 4, no spontaneous locomotor activity or barrel rolling. If no deficit was observed, the animal was removed from additional study. At $22 \mathrm{hr}$ of reperfusion, the brain was harvested for pathological examination.

In separate animal cohorts, femoral arterial blood pressure and cortical perfusion [laser Doppler flowmetry (LDF)] were evaluated throughout MCAO and early reperfusion as described previously (Sampei et al., 2000). Femoral arterial blood gases, glucose, and hemoglobin were measured at baseline and during occlusion.

Terminal histopathology. Infarction volume was analyzed by $2,3,5$ triphenyltetrazolium staining in five $2 \mathrm{~mm}$ slices. Infarction volume was determined by video microscopy and image analysis (Inquiry 3; Loats Associates, Westminster, MD), as described previously (Sampei et al., 2000).

Ovariectomy and hormone treatments. Ovariectomy was performed in ArKO WT littermates (experiment 1 ) or C57BL/6 mice (experiment 2) $\sim 2$ weeks before ischemia as described previously (Sawada et al., 2000). Estradiol was delivered by subcutaneous SILASTIC capsule $(0.062$ inch inner diameter; 0.125 inch outer diameter) filled with either $0.035 \mathrm{ml}$ of sesame oil or $17 \beta$-estradiol ( $180 \mu \mathrm{g} / \mathrm{ml}$; Sigma) (Dubal et al., 2001) beginning $7 \mathrm{~d}$ before the experiment. $17 \beta$-Estradiol and total testosterone

\section{Laser Doppler Flow}

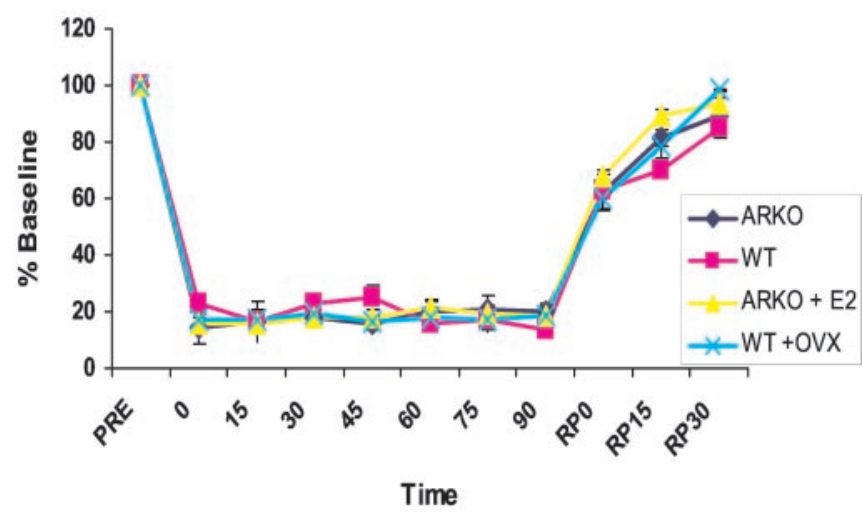

Figure 1. Relative reduction in cortical cerebral blood flow in female mice as measured by LDF in experiment 1. Baseline LDF is expressed as $100 \%$. Equivalent reductions are seen at the time of occlusion (time 0 ) and during the $90 \mathrm{~min}$ stroke. Cerebral blood flow recovery during reperfusion (RP) was also equivalent between the four groups (ArKO, WT, E2, and OVX).

levels were measured by radioimmunoassay (Diagnostic Products), as described previously (Alkayed et al., 2000).

Statistical analysis. All data are expressed as mean \pm SEM. Physiological variables and histology were analyzed by one-way ANOVA with a post hoc Newman-Keuls test to correct for multiple comparisons. Postischemic neurological scores were analyzed by the Mann-Whitney $U$ test. Plasma estradiol values were analyzed by Student's $t$ test.

\section{Results}

\section{Physiological parameters are normal in ArKOs and} equivalent in all study groups

Baseline arterial blood pressure and physiological parameters were normal in ArKO mice (data not shown). There were no differences during MCAO among treatment groups, and all variables remained within physiological range (Table 1 ). In randomly cycling, ovary-intact WT littermates, estradiol levels were $51.3 \pm$ $8.7 \mathrm{pg} / \mathrm{ml}$. As expected, plasma estradiol levels were below assay detection in both ArKOs and ovariectomized WT female mice. Testosterone levels were elevated in ArKO females (ArKO, $1331 \pm 486 \mathrm{pg} / \mathrm{ml} ; n=4)$ versus WT littermates $(117 \pm 5.1$ $\mathrm{pg} / \mathrm{ml} ; n=5)$. Estradiol in ArKO females supplemented with exogenous estrogen 1 week before stroke was physiologically relevant $(65.1 \pm 19 \mathrm{pg} / \mathrm{ml})$. The intra-ischemic laser Doppler flow signal was reduced equivalently in all groups (Fig. 1). No differences in these variables were present in fadrozole- versus vehicletreated mice (data not shown). As expected, plasma estradiol was lower in fadrozole-treated mice versus saline-treated controls $(1.4 \pm 0.07$ vs $16 \pm 4 \% ; p<0.01)$.

Ischemic damage depends in part on extragonadal estradiol; ArKO mice are highly sensitive to cerebral ischemia but respond to exogenous estradiol

Premature mortality (death before endpoint) was higher in ArKO (4 of 13 studied) compared with WT (1 of 12 studied). As 


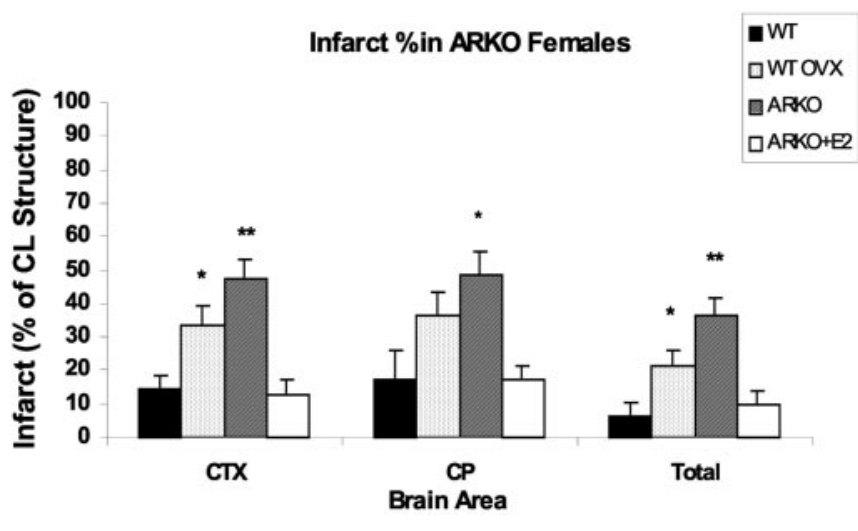

Figure 2. Total and regional infarction [percentage of contralateral $(\mathrm{CL})$ structure] in female mice. ArKO mice had significantly greater ischemic damage in both the cortex (CTX) and caudate-putamen (CP) compared with ovary-intact WT mice. ArKO females also had significantly more total and cortical damage than ovariectomized WT mice. Supplementation of ArKO females with E2 ameliorated ischemic damage to levels seen in intact WT mice. ${ }^{*} p<0.05$; ${ }^{* *} p<0.01$ ).

expected, total, cortical, and striatal ischemic damage was increased in ovariectomized WT females compared with ovaryintact, random cycling WT females (Fig. 2). Similarly, damage in all brain regions was larger in ArKO versus intact WT females $(p<0.01)$, demonstrating the ischemic vulnerability of ArKO animals with complete loss of $17 \beta$-estradiol biosynthesis. We also compared injury size in the ArKO with that observed in ovariectomized WT as a means of assessing the importance of nonovarian estradiol to ischemic outcome. Total and cortical infarction was increased in ArKO versus ovariectomized WT $(p<$ $0.01)$; however, there was no difference observed in the striatum $(p<0.27)$. Chronic estradiol treatment completely reversed ArKO ischemic vulnerability in all brain areas. Accordingly, infarction volumes in estradiol-treated ArKO were not different from intact WT females. Neurological scores at $22 \mathrm{hr}$ reflected these differences in infarct size; ovary-intact females had low neurological scores of $1.4 \pm 0.3$, similar to estrogen-treated ArKOs (1.5 \pm 0.2 ), compared with $2.9 \pm 0.1$ in OVX WT and $3.3 \pm 0.3$ in ArKO females.

\section{Aromatase inhibitor fadrozole also increases ischemic vulnerability}

Mice treated with fadrozole for $7 \mathrm{~d}$ before ischemia sustained larger damage as assessed by total $(p<0.01)$, cortical $(p<0.01)$, or striatal infarction volume $(p<0.01)$ relative to vehicle-treated controls (Fig. 3). Neurological scores at $22 \mathrm{hr}$ reflected differences observed in histological outcome. Consistent with the increased severity of tissue damage, neurological score was increased (worsened) in fadrozole-treated mice (fadrozole, $3.2 \pm 0.2$ vs vehicle, $1.5 \pm 0.2$ ). To further assess the contribution of extragonadally produced E2, ovary-intact C57BL/6 female mice received fadrozole, and ischemic outcome was compared with ovariectomized, saline-treated C57BL/6 females. Fadrozole-treated animals sustained larger total (fadrozole, $49 \pm 1.3 \%$ vs OVX, $30 \pm$ $1.6 \% ; p<0.01$ ), cortical (fadrozole, $59 \pm 2.3 \%$ vs OVX, $35 \pm$ $1.9 \% ; p<0.01$ ), and striatal infarcts (fadrozole, $59.8 \pm 3.6 \%$ vs OVX, $37 \pm 3.6 \%$; $p<0.01$ ), as well as increased neurological severity scores relative to saline-treated OVX females (fadrozole, $3.4 \pm 0.02$ vs OVX, $2.6 \pm 0.01)$.

\section{Discussion}

This study demonstrates three important findings. First, estradiol synthesized from precursor androgens plays an important role in
Infarct \% $\square$ Oil

Fadrazole

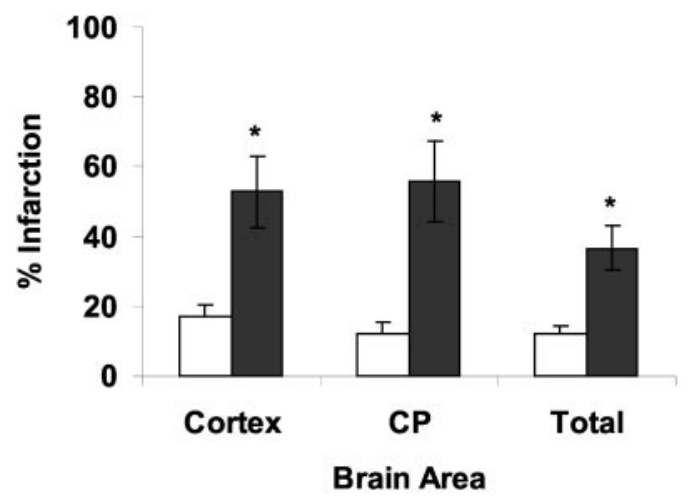

Figure 3. WT female mice treated with the aromatase inhibitor fadrozole had significantly larger infarcts (as measured as a percentage of the contralateral structure) compared with oil-treated mice in both the cortex and caudate-putamen (CP). ${ }^{*} p<0.01$.

neuroprotection after stroke. Female ArKO mice have significantly increased ischemic damage in all of the brain areas examined compared with WT randomly cycling littermates. The same result is observed when enzymatic estradiol production is pharmacologically inhibited (fadrozole), suggesting that ArKO sensitivity to ischemic injury is not attributable to properties of the gene deletion technique used in the knock-out model or in ArKO developmental physiology. Although the enzyme has elicited much interest in neurobiology, it is increasingly clear that there is also relevance to trauma (Garcia-Segura et al., 1999), chemical injury (Azcoitia et al., 2001), and, from the present observations, an apparent role in complex ischemic pathology. After stabwound injury, astroglial aromatase expression increases as part of the repair process (Garcia-Segura et al., 1999). This source of enhanced estradiol production likely benefits toxin-injured hippocampus (Azcoitia et al., 2001). Recent reports in normal brain have begun to characterize aromatase localization (e.g., presynaptic boutons) and the cell type initiating aromatization (astrocytes and neurons but not oligodendrocytes) (Balthazart and Ball, 1998). Regulation of aromatase activity in brain can be rapidly varied by ATP-dependent phosphorylation (Balthazart et al., 2001), although the specific phosphorylation sites have not yet been identified.

Second, physiologically relevant, chronic estradiol replacement in female ArKOs restores neuroprotection to a level equivalent to WT females. The effects of acute steroid exposure or treatment with supraphysiological doses were not examined. ArKO females from conception onward are unable to synthesize estradiol, leading to complex changes in sexual behavior, adiposity, bone mineralization, and reproduction (Fisher et al., 1998; $\mathrm{Oz}$ et al., 2000). These abnormalities are reversible by estradiol if administered in the early postnatal period (Fisher et al., 1998; Misso et al, 2003), suggesting that control by estradiol availability rather than by rising levels of androgen precursors or by loss of estrone production is responsible for these deficits. This is consistent with our observation that estradiol replacement reverses ischemic vulnerability in these females.

A third finding is the new observation that endogenous extragonadal estradiol production is important to the female for neuroprotection. Although gonadal estrogen loss in ovariectomized females led to an expected exacerbation of ischemic damage, this heightened damage remained less than that observed in 
ArKOs with no sites of estradiol biosynthesis. Plasma estradiol was equivalently low in both animal cohorts, suggesting that systemic estradiol delivery with penetration into the ischemic regions cannot explain differences in outcome. To examine the role of extragonadal E2 in animals not genetically altered, we compared ovary-intact fadrozole-treated C57BL/6 females to ovariectomized vehicle-treated females. Similar to ArKO mice, fadrozole-treated C57BL/6 females fared significantly worse after experimental stroke compared with ovariectomized females, again emphasizing the importance of non-ovarian E2 in ischemic neuroprotection. These simple bioassays suggest that local estradiol production alters ischemic pathophysiology. It should be emphasized that female sex steroids can be synthesized from precursor steroids in many cell and tissue types, including adipocytes, bone, vascular endothelium, and brain. In premenopausal women and estrous animals, the principal source of estradiol is ovarian; however, during reproductive senescence, significant amounts of estradiol are produced extragonadally. Central conversion of androgen to estrogen is known to play an important role in many physiological processes, including activation of sex behavior and sexual differentiation of brain in both males and females. In aging, local estrogen synthesis via the aromatase is thought to be important to cognitive function in women (Bulun et al., 1999). The present data emphasize that local synthesis must be considered in understanding sex steroids and neuropathology. Although the present study did not evaluate male mice, there is some evidence that aromatization plays an important role in the male response to excitotoxic injury (Azcoitia et al., 2001). Testosterone or estradiol, but not a non-aromatizable androgen, can reverse hilar neuronal damage after domoic acid injection, whereas genetic or pharmacological enzyme inhibition increases cell death.

Although it is possible that increased testosterone in ArKO females rather than the loss of E2 accounted for increased ischemic injury (experiment 1), this seems unlikely. First, restoration of physiologically relevant E2 levels in the ArKO mice restored completely the neuroprotection enjoyed by WT female littermates. Second, it is unclear whether testosterone exacerbates ischemic injury, and several reports indicate that the androgen is, in fact, protective in cerebral injury (Azcoitia et al., 2001). Castrated male rats sustain significantly more damage after kainic acid injection than do intact males, an effect reversed by testosterone administration. In vitro, testosterone protects human primary neuronal culture from serum deprivation-induced apoptosis (Hammond et al., 2001).

As with all transgenic strains, differences in physiology require cautious interpretation of the data. In our experiments, physiological parameters were similar both at baseline and intraischemically in all groups, including cortical LDF. We recognize that LDF is a good objective measure of advent of occlusion and reperfusion but is not fully adequate to quantify regional differences in cerebral blood flow in ArKO versus WT over time. Intraischemic and post-ischemic estrogen has numerous vascular effects (McCullough et al., 2001), and we cannot completely exclude the possibility of subtle yet meaningful changes in cortical or striatal blood flow. ArKO mice also have increased adiposity, as well as elevated serum insulin and cholesterol. Serum glucose levels were similar during stroke in all of our animals (Table 1); however, the long-term effect of hyperinsulinemia and hypercholesterolemia on stroke recovery is unclear. Last, development in a chronically estradiol-deficient state leads to ER $\alpha$ subtype upregulation $(\mathrm{ER} \alpha)$ in the ArKO forebrain (Agarwal et al., 2000). Furthermore, post-ischemic upregulation of ER $\alpha$ in cortex has been reported previously (Dubal et al., 2001), an ER that is well represented in the developing brain but sparsely present in adult cortex under ordinary conditions. ER $\alpha$ upregulation could be important to our results if "supersensitivity" to estradiol replacement and enhanced $\mathrm{ER} \alpha$ signaling occur. Our results indicate that there were no differences in ischemic damage between estrogen-replaced ArKOs and ovary-intact WT littermates. This lack of difference suggests that compensatory supersensitivity did not appear to have a large effect.

We confirmed the results in our knock-out mice by pharmacological inhibitor studies using a reversible competitive inhibitor of the P450 aromatase, fadrozole. The effectiveness of this compound in reducing estrogen biosynthesis has been demonstrated both in vivo and in vitro (Steele et al., 1987; Wozniak et al., 1992; Zumpe et al., 1993; Clancy and Michael, 1994; Wade et al., 1994). Fadrazole reduces aromatase activity in vitro and in vivo in brain homogenates to $99 \%$ of baseline after single injection (Wade et al., 1994). Aromatase inhibitors are currently used in treating estrogen-responsive breast cancer in post-menopausal women, but their nontissue-specific action has led to concern for a detrimental impact in brain and other sites (Simpson et al., 2002). The present data in rodents would support the possibility that aromatase inhibitors could have negative impact on ischemic pathology in females. However, it should also be recognized that the enzyme is expressed in a tissue-specific manner and that responses to aromatase inhibitors are difficult to predict a priori (Kamat et al., 2002). For example, the gene CYP 19 contains not only exons 2-10 that code for the protein but several alternative first exons that encode unique and tissue-specific $5^{\prime}$ untranslated regions. Alternative promoter analysis is actively under investigation for development of new aromatase inhibitors.

At this juncture, estradiol has been widely shown to be an extremely potent neuroprotectant in the laboratory, even when administered after prolonged ischemia and reperfusion (McCullough et al., 2001) (for review, see McCullough and Hurn, 2003); however, recent clinical trials of estradiol have yielded quite disappointing results (Viscoli et al., 2001; Writing Group for the Women's Health Initiative, 2002). Accordingly, it is important to dissect more carefully the mechanisms behind endogenous neuroprotection supplied by native estrogens. These studies emphasize that, as in sexual behavior and differentiation, non-ovarian estradiol supply (and possibly utilization) can influence ischemic neuronal vulnerability. We conclude that the $\mathrm{P} 450$ aromatase plays an important role in endogenous estradiol-mediated protective mechanisms and presents a novel target for neuroprotective therapy in ischemic pathology.

\section{References}

Agarwal VR, Sinton CM, Liang C, Fisher C, German DC, Simpson ER (2000) Upregulation of estrogen receptors in the forebrain of aromatase knockout (ArKO) mice. Mol Cell Endocrinol 162:9-16.

Alkayed NJ, Harukuni I, Kimes AS, London ED, Traystman RJ, Hurn PD (1998) Gender-linked brain injury in experimental stroke. Stroke 29:159-165.

Alkayed NJ, Murphy SJ, Traystman RJ, Hurn PD, Miller VM (2000) Neuroprotective effects of female gonadal steroids in reproductively senescent female rats. Stroke 31:161-168.

Azcoitia I, Sierra A, Veiga S, Honda S, Harada N, Garcia-Segura LM (2001) Brain aromatase is neuroprotective. J Neurobiol 47:318-329.

Bakker J, Honda S, Harada N, Balthazart J (2002) The aromatase knock-out mouse provides new evidence that estradiol is required during development in the female for the expression of sociosexual behaviors in adulthood. J Neurosci 22:9104-9112.

Balthazart J, Ball GF (1998) New insights into the regulation and function of brain estrogen synthase (aromatase). Trends Neurosci 21:243-249. 
Balthazart J, Baillien M, Ball GF (2001) Phosphorylation processes mediate rapid changes of brain aromatase activity. J Steroid Biochem Mol Biol 79:261-277.

Bonsall RW, Clancy AN, Michael RP (1992) Effects of the non-steroidal aromatase inhibitor, fadrozole on sexual behavior in male rats. Horm Behav 26:240-254.

Bulun SE, Zeitoun K, Sasano H, Simpson ER (1999) Aromatase in aging women. Semin Reprod Endocrinol 17:349-358.

Carswell HV, Dominiczak AF, Macrae IM (2000) Estrogen status affects sensitivity to focal cerebral ischemia in stroke-prone spontaneously hypertensive rats. Am J Physiol Heart Circ Physiol 278:H290-H294.

Clancy AN, Michael RP (1994) Effects of testosterone and aromatase inhibition on estrogen receptor-like immunoreactivity in male rat brain. Neuroendocrinology 59:553-560.

Dubal DB, Zhu H, Yu J, Rau SW, Shughrue PJ, Merchenthaler I, Kindy MS, Wise PM (2001) Estrogen receptor alpha, not beta, is a critical link in estradiol-mediated protection against brain injury. Proc Natl Acad Sci USA 98:1952-1957.

Fisher CR, Graves KH, Parlow AF, Simpson ER (1998) Characterization of mice deficient in aromatase (ArKO) because of targeted disruption of the cyp19 gene. Proc Natl Acad Sci USA 95:6965-6970.

Garcia-Segura LM, Wozniak A, Azcoitia I, Rodriguez JR, Hutchison RE, Hutchison JB (1999) Aromatase expression by astrocytes after brain injury: implications for local estrogen formation in brain repair. Neuroscience 89:567-578.

Hammond J, Le Q, Goodyer C, Gelfand M, Trifiro M, LeBlanc A (2001) Testosterone-mediated neuroprotection through the androgen receptor in human primary neurons. J Neurochem 77:1319-1326.

Jones ME, Thorburn AW, Britt KL, Hewitt KN, Wreford NG, Proietto J, Oz OK, Leury BJ, Robertson KM, Yao S, Simpson ER (2000) Aromatasedeficient (ArKO) mice have a phenotype of increased adiposity. Proc Natl Acad Sci USA 97:12735-12740.

Kamat A, Hinshelwood MM, Murry BA, Mendelson CR (2002) Mechanisms in tissue-specific regulation of estrogen biosynthesis in humans. Trends Endocrinol Metab 13:122-128.

Lephart ED (1996) A review of brain aromatase cytochrome P450. Brain Res Rev 22:1-26.

Lephart ED, Lund TD, Horvath TL (2001) Brain androgen and progesterone metabolizing enzymes: biosynthesis, distribution and function. Brain Res Rev 37:25-37.

MacLusky NJ, Walters MJ, Clark AS, Toran-Allerand CD (1994) Aromatase in the cerebral cortex, hippocampus, and midbrian: ontogeny and developmental implications. Mol Cell Neurosci 5:691-698.

McCullough LD, Hurn PD (2003) Estrogen and neuroprotection: an integrated view. Trends Endocrinol Metab 14:228-235.

McCullough LD, Alkayed NJ, Traystman RJ, Williams MJ, Hurn PD (2001) Postischemic estrogen reduces hypoperfusion and secondary ischemia after experimental stroke. Stroke 32:796-802.
Misso ML, Murata Y, Boon WC, Jones ME, Britt KL, Simpson ER (2003) Cellular and molecular characterization of the adipose phenotype of the aromatase-deficient mouse. Endocrinology 144:1474-1480.

Oz OK, Zerwekh JE, Fisher C, Graves K, Nanu L, Millsaps R, Simpson ER (2000) Bone has a sexually dimorphic response to aromatase deficiency. J Bone Miner Res 15:507-514.

Robertson KM, O’Donnell L, Jones ME, Meachem SJ, Boon WC, Fisher CR, Graves KH, McLachlan RI, Simpson ER (1999) Impairment of spermatogenesis in mice lacking a functional aromatase (cyp 19) gene. Proc Natl Acad Sci USA 96:7986-7991.

Rusa R, Alkayed NJ, Crain BJ, Traystman RJ, Kimes AS, London ED, Klaus JA, Hurn PD (1999) 17beta-estradiol reduces stroke injury in estrogendeficient female animals. Stroke 30:1665-1670.

Sampei K, Goto S, Alkayed NJ, Crain BJ, Korach KS, Traystman RJ, Demas GE, Nelson RJ, Hurn PD (2000) Stroke in estrogen receptor-alphadeficient mice. Stroke 31:738-743.

Sawada M, Alkayed NJ, Goto S, Crain BJ, Traystman RJ, Shaivitz A, Nelson RJ, Hurn PD (2000) Estrogen receptor antagonist ICI182, 780 exacerbates ischemic injury in female mouse. J Cereb Blood Flow Metab 20:112-118

Simpson ER, Clyne C, Rubin G, Boon WC, Robertson K, Britt K, Speed C, Jones M (2002) Aromatase-a brief overview. Annu Rev Physiol 64:93-127.

Steele RE, Mellor LB, Sawyer WK, Wasvary JM, Browne LJ (1987) In vitro and in vivo studies demonstrating potent and selective estrogen inhibition with the nonsteroidal aromatase inhibitor CGS 16949A. Steroids 50:147-161.

Stoffel-Wagner B, Watzka M, Schramm J, Bidlingmaier F, Klingmuller D (1999) Expression of CYP19 (aromatase) mRNA in different areas of the human brain. J Steroid Biochem Mol Biol 70:237-241.

Viscoli CM, Brass LM, Kernan WN, Sarrel PM, Suissa S, Horwitz RI (2001) A clinical trial of estrogen-replacement therapy after ischemic stroke. New Engl J Med 345:1243-1249.

Wade J, Schlinger BA, Hodges L, Arnold AP (1994) Fadrozole: potent and specific inhibitor of aromatase in the zebra finch brain. Gen Comp Endocrinol 94:53-61.

Wozniak A, Holman SD, Hutchinson JB (1992) In vitro potency and selectivity of the nonsteroidal androgen aromatase inhibitor CGS 16949A compared to steroidal inhibitors in the brain. J Steroid Biochem Mol Biol 43:281-287.

Writing Group for the Women's Health Initiative (2002) Risks and benefits of estrogen plus progestin in healthy postmenopausal women. Principal results from the Women's Health Initiative randomized controlled trial. JAMA 288:321-333.

Zumpe D, Bonsall RW, Michael RP (1993) Effects of the nonsteroidal aromatase inhibitor, fadrozole, on the sexual behavior of male Cynomolgus monkeys (Macaca fasicicularis). Hormones Behav 27:200-215. 